\title{
Modeling of an isolated microgrid with hybrid PV-BESS system for peak load shaving simulation
}

\author{
Md Masud Rana*, Mohd Fakhizan Romlie, Mohd Faris Abdullah, Moslem Uddin and Mohammad \\ Obaidur Rahman \\ Center for Smart Grid Energy Research (CSMER), Electrical and Electronics Engineering Department, \\ Universiti Teknologi PETRONAS, 32610, Bandar Seri Iskandar, Perak, Malaysia
}

Received: 22-September-2020; Revised: 11-February-2021; Accepted: 14-February-2021

(C)2021 Md Masud Rana et al. This is an open access article distributed under the Creative Commons Attribution (CC BY) License, which permits unrestricted use, distribution, and reproduction in any medium, provided the original work is properly cited.

\begin{abstract}
In this paper, a simplified model of an isolated microgrid (IMG) with hybrid photovoltaic (PV)-battery energy storage system (BESS) is discussed. The concept of peak load shaving is also demonstrated. The developed model helps an isolated power system to minimize the demand and maximize the economic benefit. MATLAB/Simulink tool was used to simulate the electrical circuit of the IMG system. The IMG model contains four sub-systems, namely the PV model, time varying load profile model, BESS model and gas turbine generator (GTG) dispatch model. To evaluate the performance of the developed IMG, a simulation case study was conducted under realistic load conditions of Universiti Teknologi PETRONAS (UTP). Results indicated that simulation illustrates the precise situation of the real-time system, as found in the UTP microgrid. Results also revealed that the concept of peak load shaving broadly illustrated in this study. The implementation of the proposed IMG model may bring economic benefit by minimizing peak load demand.
\end{abstract}

\section{Keywords}

Isolated microgrid system, Photovoltaic, Battery energy storage system, Peak load shaving, Hybrid system modelling.

\section{Introduction}

Nowadays, the maximum percentage of total energy generation all over the world is highly dependent on the conventional energy generation sources like gas turbine generator, coal generator, diesel generator and etc. [1-3]. Due to the generation of power from these type of generators, environmental issues are associated highly [4-6]. To reduce the stress of the environment, distributed energy resources (DER) are introduced increasingly [7, 8]. Besides, the shortage of fossil fuel, increasing the price of fuel and the total operation cost of the system are also some reasons to move on the DER [9-11].

For the IMG system, the power generation from renewable energy sources like PV, hydro-energy, geothermal energy is becoming more popular in recent time [12-14]. For a small-scale IMG system, $\mathrm{PV}, \mathrm{BESS}$, conventional generator, different types of switches, inverter, converter, circuit breaker, transformer etc. are connected which can make the system complex and bulky.

*Author for correspondence

352
So, this type of IMG system requires proper control techniques for reliable and stable operation. The control techniques of an IMG system can be found in [15]. IMG is an essential part of the power system, but in existing literature, very few approaches have been identified to improve its operation [16].

For proper operation and control of the system under peak load shaving application, proper IMG system design is the primary requirement. In this paper, we are going to show an appropriate IMG design for peak shaving service with hybrid PV-BESS system. The system has been designed in MATLAB/Simulink environment. The complete system has four different significant components; PV, BESS, time varying load, and GTG. Every component has been designed separately, and after that, they are sandwiched together to form a complete system. The outcomes of the system have been found from the simulation, and it shows that the model is highly appropriate for the IMG system for peak shaving service. The results exhibit the potentiality of the system. 
This paper is organized as: In Section 2, a coherent literature review is presented. The details of the test microgrid system and the designed IMG with hybrid PV-BESS in MATLAB/Simulink have been presented in Section 3. The simulation results and discussion of this work are discussed in section 4 . Finally, the conclusion and future recommendations have been discussed in section 5 .

\section{Literature review}

Peak load presents a key challenge to the microgrids. Application of hybrid PV-BESS is one of the most attractive potential strategies to mitigate this challenge. However, to make the hybrid PV-BESS beneficial for isolated microgrid it is inescapable to model IMG with PV-BESS and analyze the simulation results before implementation. Therefore, an in-depth study on IMG modeling with hybrid PVBESS is the initial requirement. In existing literature, few works have been found for power system modeling. Rameen Abdel Hady constructs a MATLAB Simulink model to represent a PV system, mounted on national water research center's roof. He simulates the model for two scenarios: local grid tied system and national grid tied system. The model shows economical savings when it implements for the national grid [17]. This work considers the model with PV system and BESS system does not consider here. Peak load shaving strategy does not consider with the constructed model. Ashraf Khalil presents a modelling and controlling strategy of PV-based Microgrid system. Two voltage source inverters are used to form the PV-based microgrid system [18]. This model is presented the power sharing of the microgrid where peak load shaving is not in the consideration. Hanane Dagdougui designs a microgrid model for a university campus microgrid to the operation and control of the microgrid. The model of the microgrid aims to minimize the overall operation costs of the system. The model ensures the power exchange with the local electrical network. [13]. Peak load shaving is not in the consideration of this work. Another campus microgrid system model is found in [4] where BESS is considered in the model for peak shaving application. Photovoltaic system is not considered there.

Overall, for peak load shaving application, a complete model for IMG with hybrid PV-BESS system for peak load shaving application is rarely found in existing literature.

\section{Microgrid system modeling}

This section presents a comprehensive overview of the test microgrid system and the designed simulation model in MATLAB/Simulink software of the test microgrid.

\subsection{System description}

UTP campus is an ideal isolated microgrid system. UTP has two gas turbine generators where every generator has $4.2 \mathrm{MW}$ rated capacity, and the optimum generation capacity is $3.8 \mathrm{MW}$. The system maintains $11 \mathrm{kV}$ generation voltage, and it distributes $415 \mathrm{~V}$ around the whole campus. It distributes the generated power around $5 \mathrm{~km}$ from the generation side to consumers. Power consumption of the UTP depends on the campus activities. The load pattern variation can be observed during weekends, semester breaks, public holidays and working days as seen in Figure 1. In a working day, the demand for power is the highest because of the highest number of students are available in their workstations and the academic classrooms. The opposite is true for the public holiday. For semester break and weekend, the load profile of UTP looks similar.

\subsection{Test microgrid designing}

A complete Microgrid model has been demonstrated in this section. This microgrid model is well fitted for the isolated power system operation. This microgrid model contains hybrid PV-BESS system which is connected as a DER unit. Two GTG's which have $4.2 \mathrm{MW}$ rated capacity and the optimum capacity is 3.8MW [19]. The PV generation unit with rated power capacity of $2 \mathrm{MW}$ and for the UTP environment, the maximum generation during day time peak period can be around 1.9MW [20]. From UTP load profile, the maximum power demand among weekends, semester break and public holiday is around 5.7MW except working day. The $2 \mathrm{MW} \mathrm{PV}$ unit and primary generator can meet the maximum demand of the mentioned scenarios and supporting generator does not need to operate $(2 \mathrm{MW}+4.2 \mathrm{MW}$ $=6.2 \mathrm{MW}$ or $1.9 \mathrm{MW}+3.8 \mathrm{MW}=5.7 \mathrm{MW}$ ). For this reason, PV unit considered as $2 \mathrm{MW}$. The BESS unit with rated capacity of $400 \mathrm{~kW}$ and rated power capacity of $900 \mathrm{kWh}$. For UTP load profile, the morning and evening peak demand varies form $3.8 \mathrm{MW}$ to $4.2 \mathrm{MW}$ for 2 hours and 15 minutes [15]. So, the power capacity of BESS unit should be $900 \mathrm{kWh}(400 \mathrm{~kW} \times 2.25 \mathrm{~h}=900 \mathrm{kWh})$ and timevarying load profile is combined with the model. 
Md Masud Rana et al.

Before operating the system, it is essential to ensure proper charge-discharge operation of BESS, optimum usage of PV and optimum generation dispatch of the GTG for economic benefit.
The system voltage is considered as $415 \mathrm{~V}$, and the system frequency is $50 \mathrm{~Hz}$. The DC-AC converter also maintains the same properties. The transmission line has been considered around $5 \mathrm{~km}$. The complete model of the IMG system has been exhibited in Figure 2.

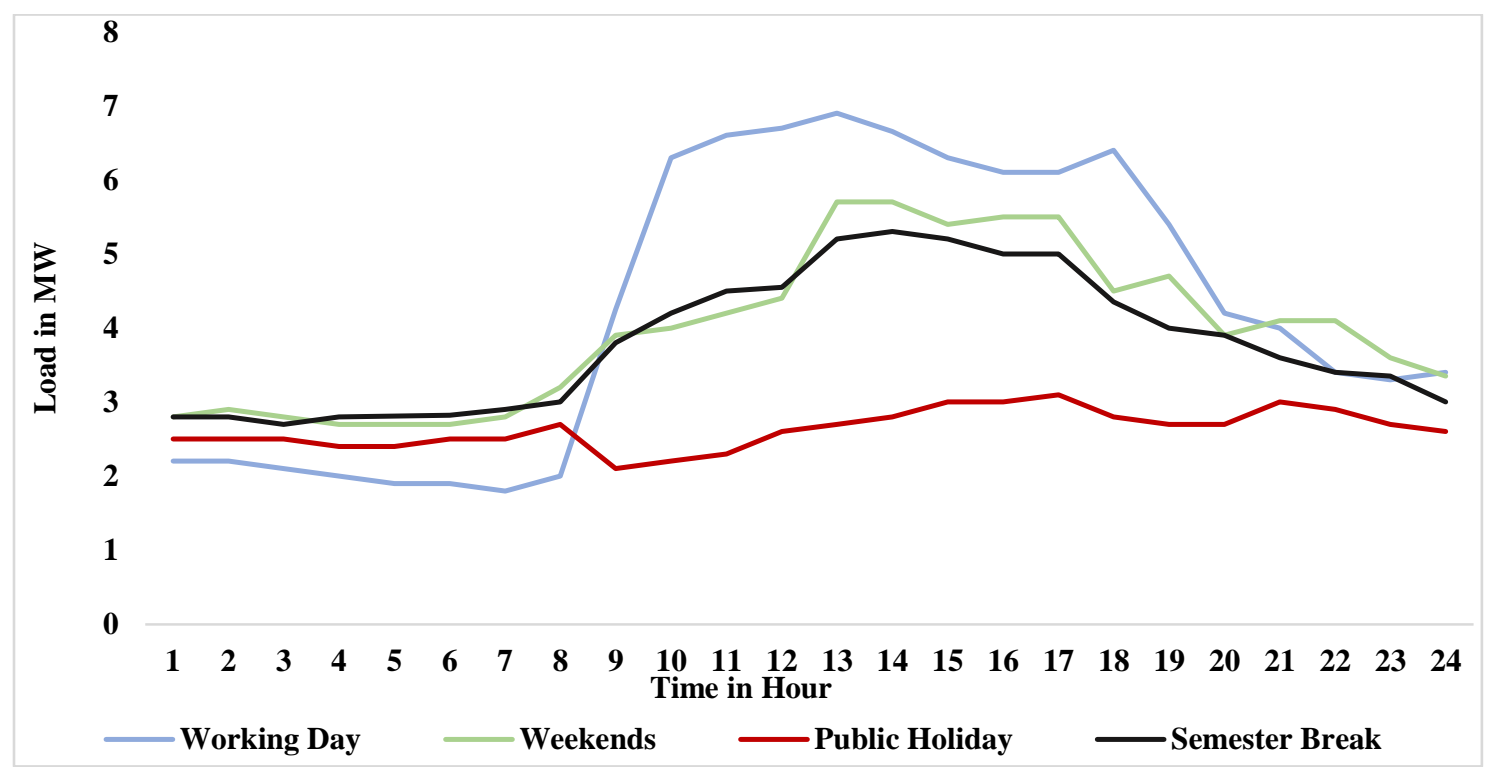

Figure 1 Typical UTP load profile for different scenarios

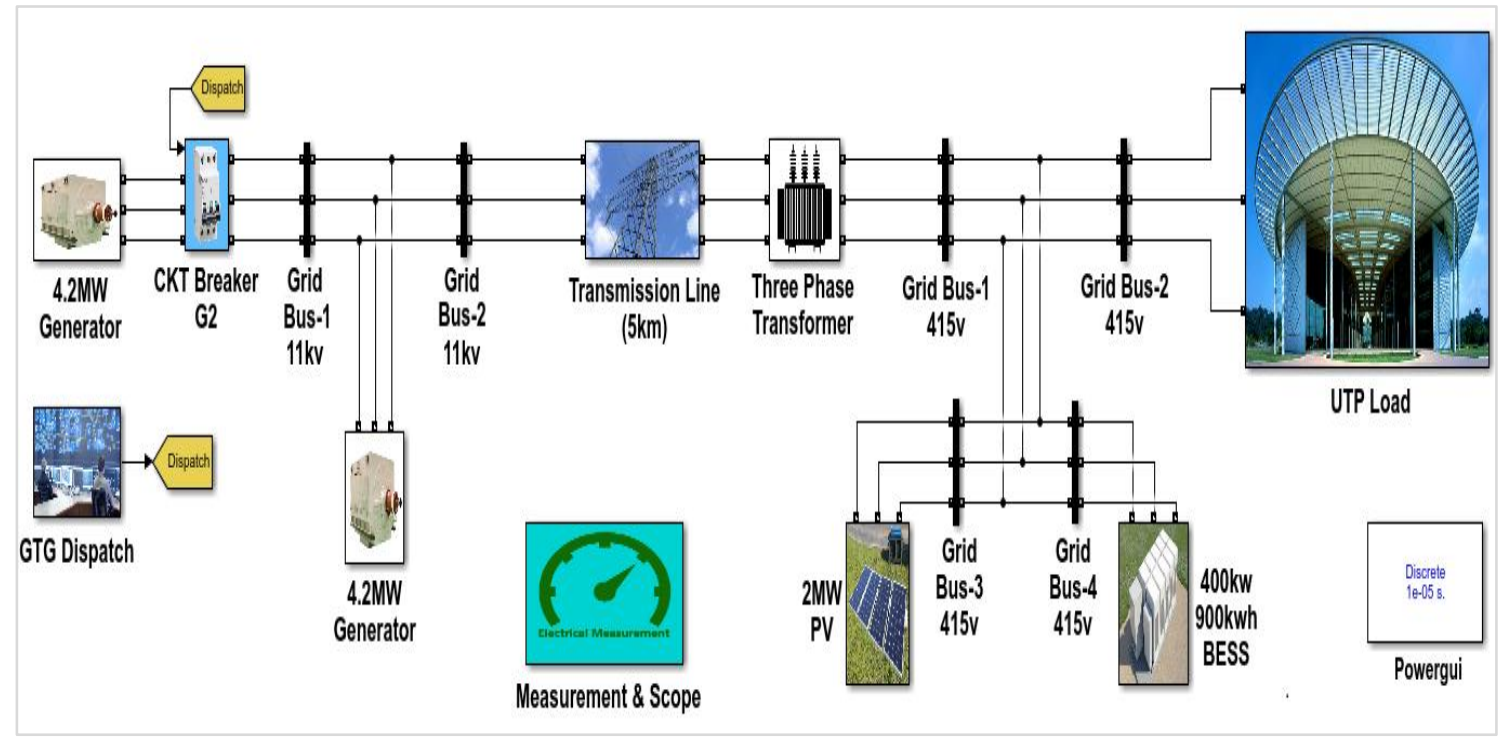

Figure 2 Complete MATLAB/Simulink model of UTP microgrid system

The complete IMG system model can be classified by four major components-
a. Time Varying Load Model
b. PV Model
c. GTG Dispatch Model
d. BESS Model

354
3.2.1Time varying load model

The time-varying load profile of the model has been considered three-phase three wires loads which will consume active and reactive power. Total 96 threephase loads are connected in parallel. After every 15 minutes, the load will be changed according to the 
pulse of the three-phase breaker. UTP microgrid has four different load profiles such as weekend load profile, semester break load profile, public holiday load profile and working day load profile. The system will realize the correct load profile of the day according to the average initial power requirement and clock pulse of the primary three-phase breaker. The dynamic load profile model has been demonstrated in Figure 3.

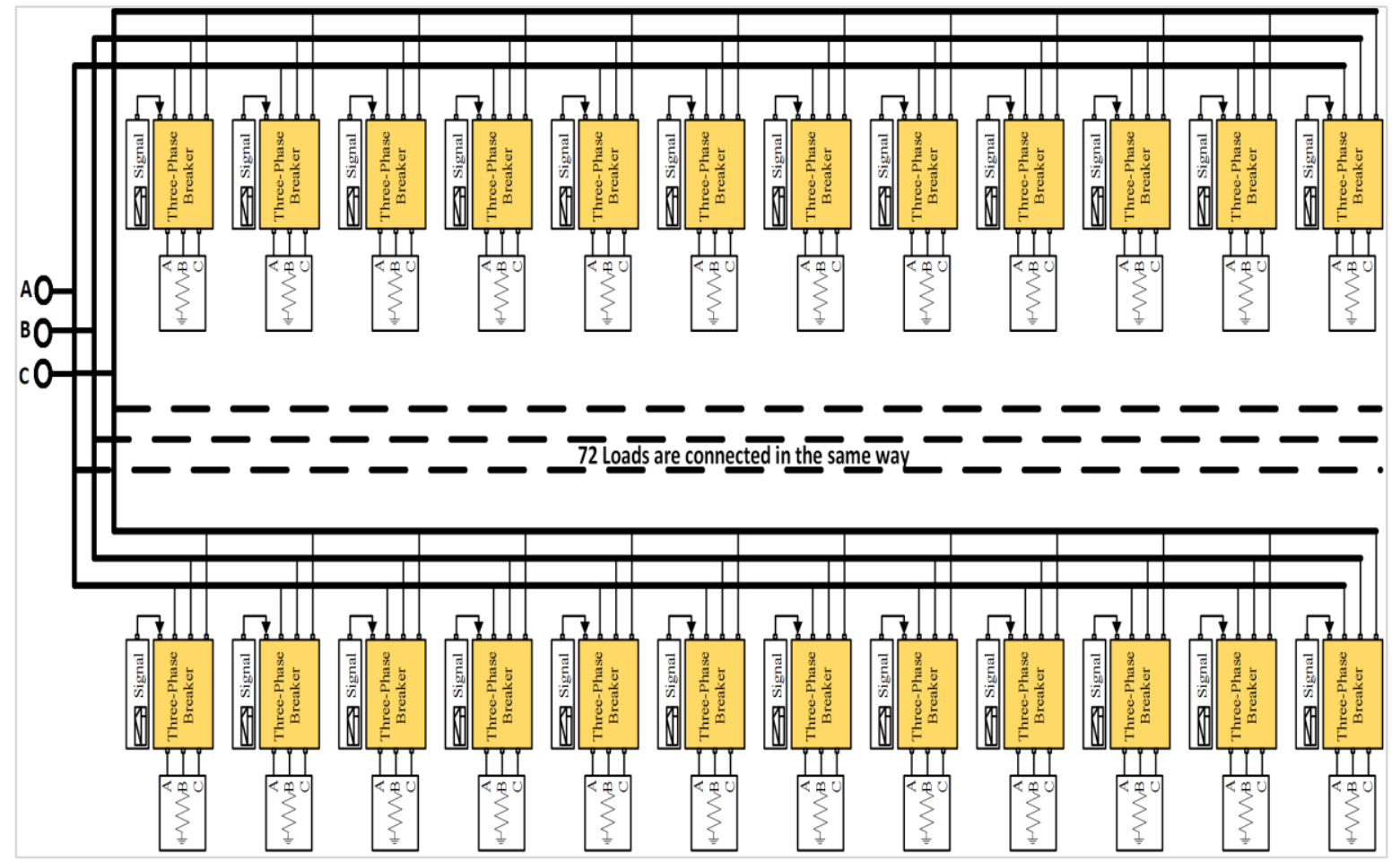

Figure 3 MATLAB/Simulink model to realize variable load profile

\subsubsection{PV model}

The PV generation unit has been considered as $2 \mathrm{MW}$, and two separate PV units relate to each other to maintain the desired power. Both PV units have the same capacity of power generation and the same properties of the DC-AC converter and LC filter. The MATLAB/Simulink model of the PV generation unit is shown in Figure 4. The output of the converter is three-phase AC power which maintains three wires to supply to the loads. The converter is a MPPT converter which has been controlled by the dynamic current- controlled P\&O algorithm. The output voltage will be constant all the time, and the output power will follow the input current profile of the converter. The inputs of the PV panels are solar irradiance and module temperature.

\subsubsection{GTG dispatch model}

The system has two GTGs where every GTG has the rated capacity $4.2 \mathrm{MW}$ and the optimum capacity $3.8 \mathrm{MW}$. The generator maintains $11 \mathrm{KV}$ generation voltage, and by using a step-down transformer, it distributes $415 \mathrm{~V}$ to the loads. The generation voltage frequency is $50 \mathrm{~Hz}$. Since the system has a PV generation unit, both GTGs do not need to operate all day long. When the PV generation is not enough along with G-1 to meet the demand, only this time, the G-2 needs to operate to meet the demand. The dispatch control operation will depend on the timevarying load profile and the generation of PV. The mathematical dispatch control model of GTG is shown in Figure 5. 


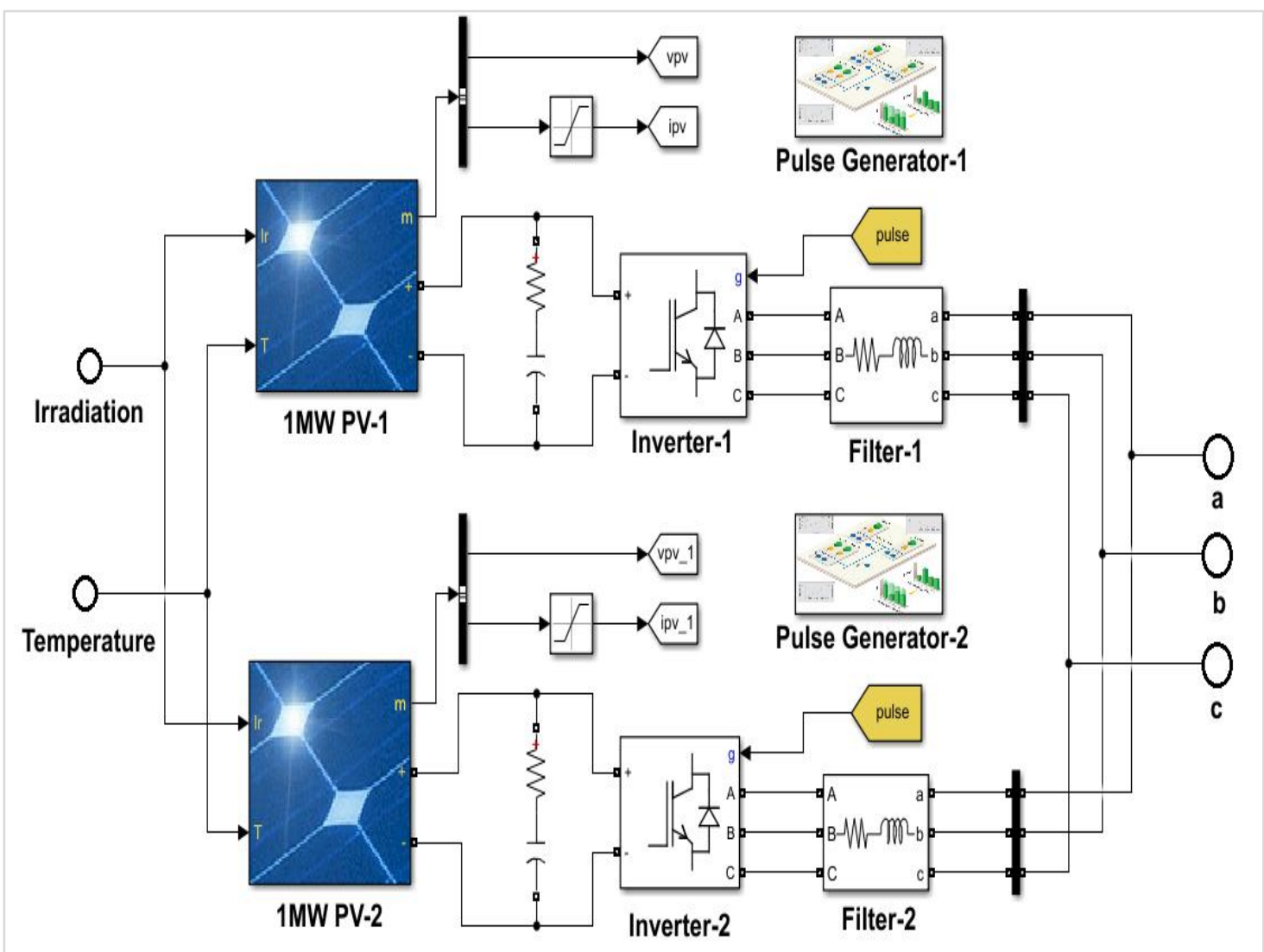

Figure 4 MATLAB/Simulink model of PV generation system

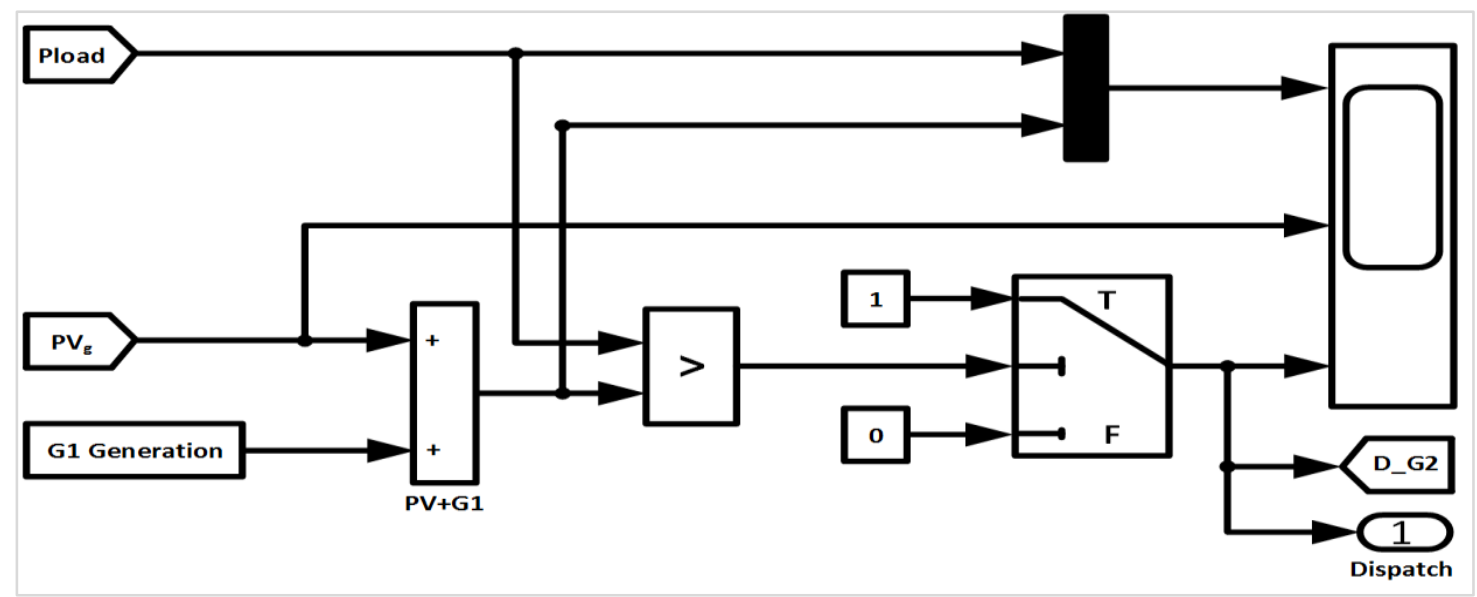

Figure 5 MATLAB/Simulink model of economic generation dispatch

\subsubsection{BESS model}

BESS has been used in the system to balance the power flow to meet the demand. The model has a BESS unit which has $400 \mathrm{KW}$ rated power. The variable load usually remains between $3.8 \mathrm{MW}$ to 4.2MW during morning and evening period, which stay around 2 hours and 15 minutes. So, the capacity of the BESS is $900 \mathrm{KWh}$. The initial state of charge 356
(SOC) of the battery is $20 \%$, and the system efficiency is around 97\%. The BESS unit has a bidirectional converter which will operate according to the direction of the charge-discharge logic. Generally, the BESS will absorb power from the generators during the off-peak period, and it will deliver the stored energy during the peak period. The SOC does not need to calculate because the Simulink 
BESS model has its own SOC calculation section. So, it can easily observe the instantaneous SOC of the battery. The MATLAB/Simulink model of BESS has been shown in Figure 6.

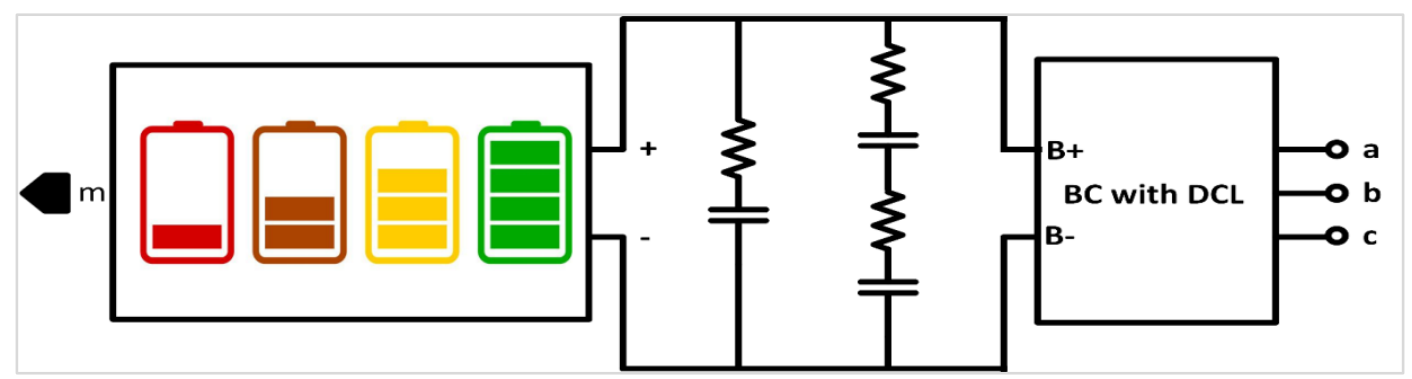

Figure 6 MATLAB/Simulink model of BESS unit

The BESS model can be classified by two major parts:

a. Bi-directional Converter model

b. Charge-Discharge Controlling model

\subsection{Bi-directional converter model}

The bi-directional converter is connected to the BESS for storing energy or to deliver energy. This converter maintains two operations by its DC-AC and AC-DC converter. This converter has been designed with
IGBT, where few operates as DC-AC converter, and few operate as AC-DC converter. The operation of the bi-directional converter will maintain the control logic of charge-discharge operation. An LC filter is connected to the three-phase line to remove unexpected noise from the output of the converter. The MATLAB/ Simulink model of the Bi-directional converter has been shown in Figure 7.

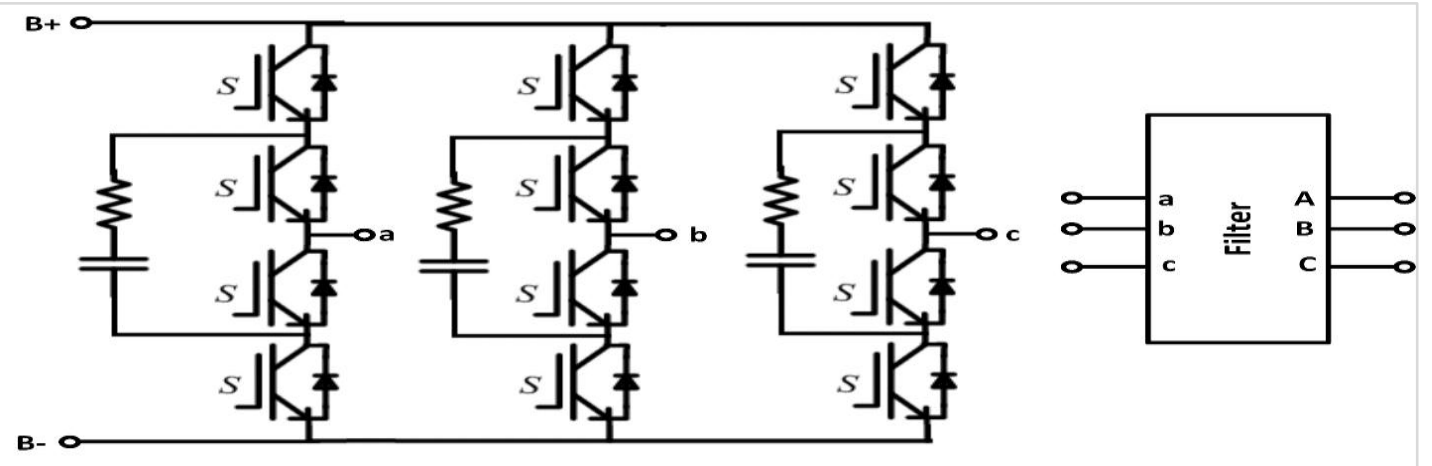

Figure 7 MATLAB/Simulink model of a bi-directional converter

\subsection{Charge-discharge controlling model}

The charge-discharge logic will be applied as the gate pulse of the IGBT to control the operation of the bidirectional converter. The charge-discharge controlling model has been designed in such a way that the BESS unit can quickly identify the charging operation or the discharging operation.

If the load is less than the total generation of PV \& GTG and if the SOC is also less than $90 \%$, this time,
BESS will be charged from the generators. On the other hand, if the load is higher than the total generation of PV \& GTG and if the SOC is greater than $20 \%$, this time BESS will be discharged. The charge-discharge control logic of the BESS has shown in Figure 8, and the charge-discharge controlling gate pulse model of the bi-directional converter has been exhibited in Figure 9 . 


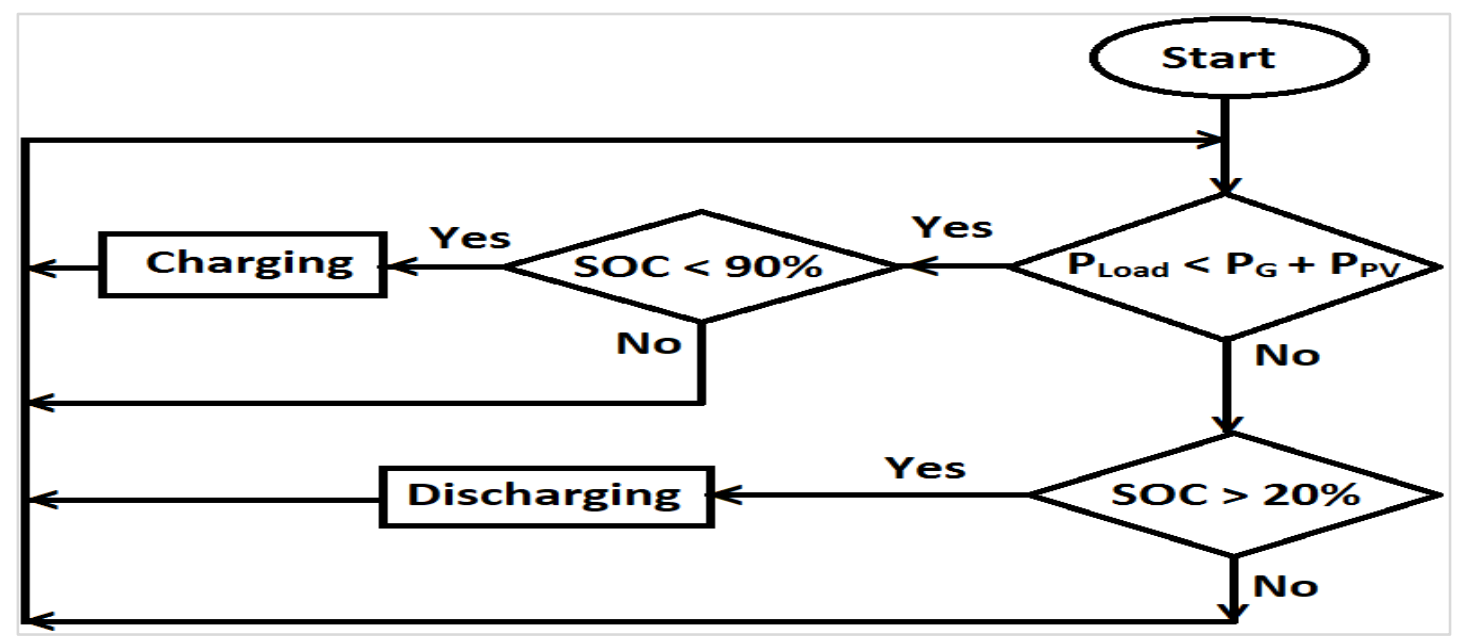

Figure 8 Flow chart of the charge-discharge control logic

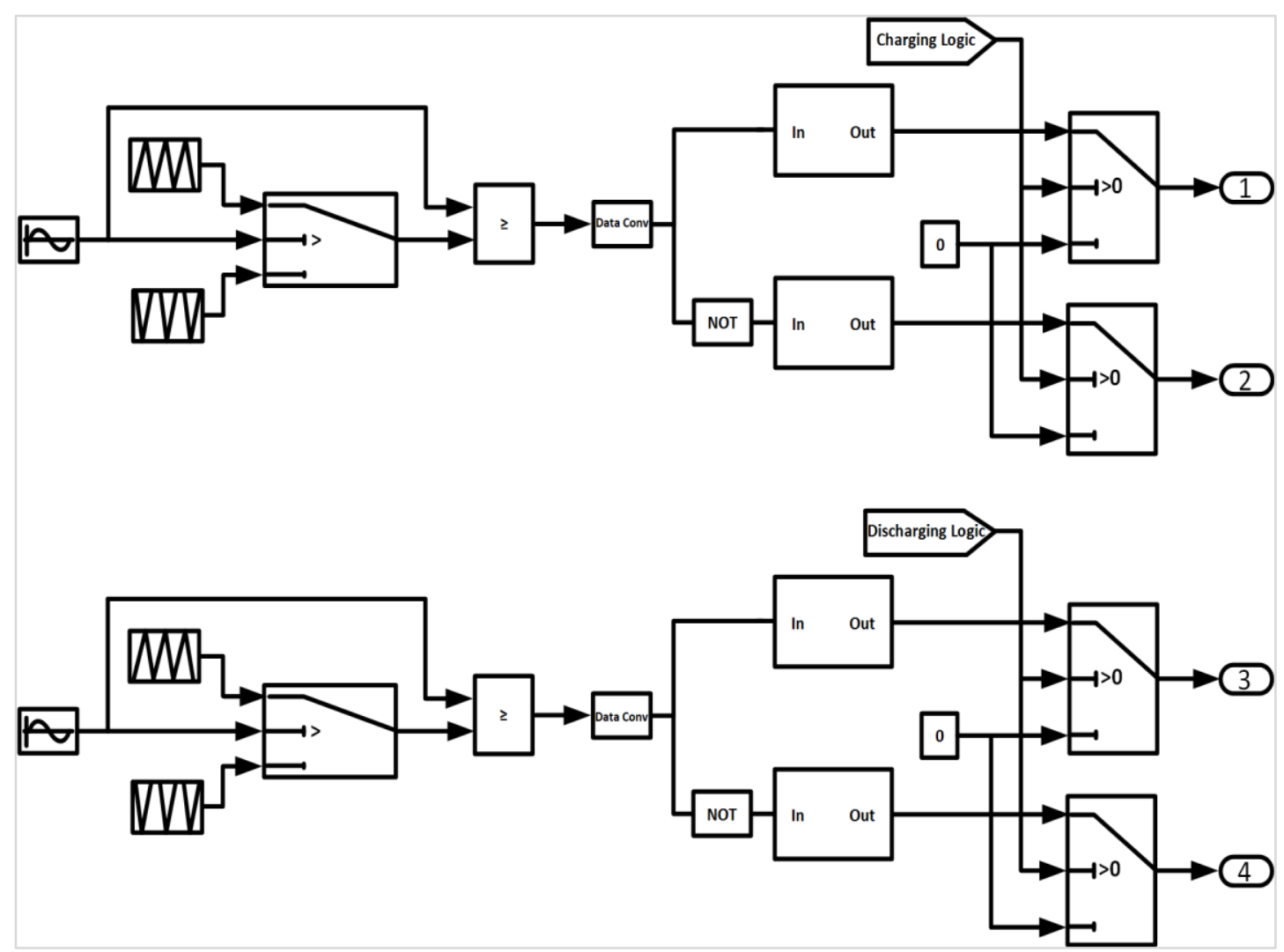

Figure 9 MATLAB/Simulink model of generating the gate pulse for bi-directional converter

\section{Simulation results and discussion}

The simulation result of the time-varying load profile model has shown in Figure 10 (a). The UTP-IMG system has four different load profile, as mentioned in the previous section. The simulation has been conducted for the semester break load profile. The exact value of electricity consumption on the semester break has been illustrated properly on the result.

The generation dispatch curve has been demonstrated in Figure $10(\mathrm{~b})$. From the figure, it can quickly identify the economic operation of the generation system. When the PV-BESS hybrid system is not available in the system, the generators need to 
operate almost the whole time of the day. Hence, the availability of hybrid PV-BESS system results in the least operation of the supporting generator, which can reduce the overall cost of the system.

The PV generation unit is considered $2 \mathrm{MW}$ in this work. The simulation result has shown the PV generation in Figure $10(\mathrm{~d})$, where it considered the real-time data of module temperature and solar irradiation.
To balance the optimum operation of the system, BESS needs to be charged and discharged. The charge-discharge logic has been shown in the previous section. The simulation result of BESS charging and discharging from the generation system has been exhibited in Figure $10(e)$. To ensure the economic operation, the load profile should be very close to its optimum value.
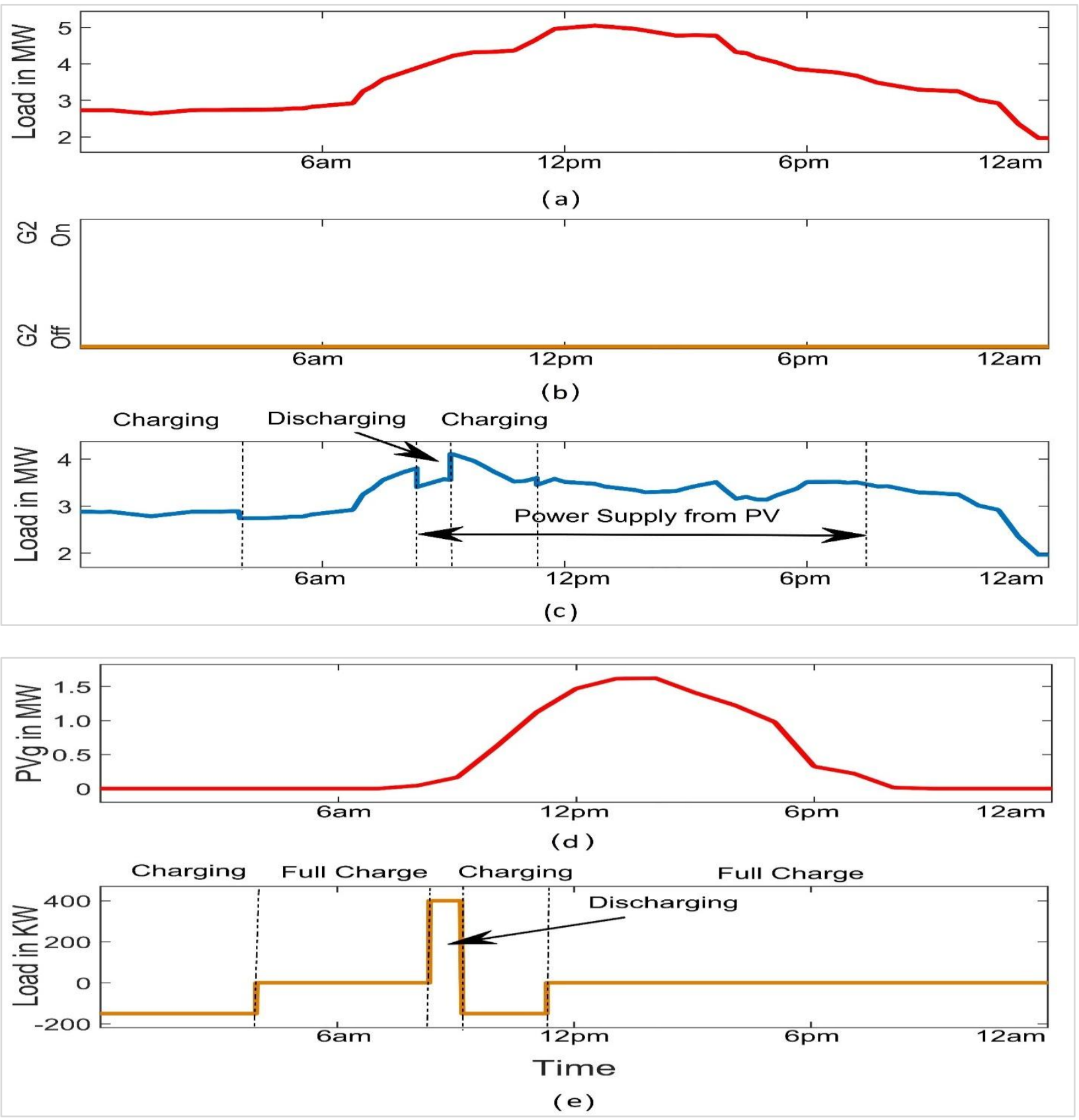

Figure 10 (a) Time varying load profile (semester break), (b) Economic generation dispatch, (c) Peak shaving operation, (d) PV generation based on real time data, and (e) BESS charging-discharging operation 
To perform the charge and discharge operation, the load profile has been maintained of its optimum value. BESS has been allowed to be charged when the demand is lower than the generation, and BESS has been allowed to be discharged when the demand is higher than the generation.

The PV-BESS hybrid system is used for minimizing the demand throughout the day. When PV is available in the system, it will supply power to the load directly. If PV generation is not enough or PV generation is not available in the system, BESS will be discharged to fulfil the demand. Again, when the SOC is below $90 \%$, BESS will be charged, and for discharge operation, it should be more than or equal $20 \%$. The simulation result of the load minimization of the system has been exhibited in Figure 10 (c).

\subsection{Limitations of this study}

This study focuses on the designing an Isolated Microgrid system model for ensuring the peak shaving services. This designed model can successfully provide the desired service and ensure the economic operation of the system. This model includes a large PV generation unit. This type of PV generation system requires a large area for installation. Besides it, there did not consider the lifetime improvement of the different components of the designed model. The components with improved lifetime can serve the system in long terms which can bring more economic benefit for the system.

\section{Conclusion and future recommendation}

In this paper, an ideal IMG system has been developed in MATLAB/Simulink environment to ensure the smooth operation of the microgrid under peak load demand. The results of this study have been discussed and analyzed in the context of UTP microgrid. The simulation results revealed that the developed IMG model approximately represent the perfect situation of the real-time system in UTP. It is also found that the variable load model can precisely characterize the different load scenarios, which is essential to demonstrate peak shaving concept. The simulation result of PV generation system shown the real-time power generation of the PV as recoded in UTP system. Further, results of this study proved that the developed IMG with hybrid PV-BESS offers more economical and environment-friendly power generation through peak shaving along with maximizing the utilization of the renewable.

However, this model did not consider the improvement of the lifetime of different components.
Therefore, the lifetime improvement of different components can be analyzed further to improve the operational period of different components which can bring more economic benefit for this system.

\section{Acknowledgment}

The authors would like to thank Universiti Teknologi PETRONAS (UTP) for providing an excellent environment for doing this research. The authors also would like to thank Yayasan Universiti Teknologi PETRONAS (YUTP) (cost centre 0153AA-H25) for providing the research grant to perform this research.

\section{Conflicts of interest}

The authors have no conflicts of interest to declare.

\section{References}

[1] Yu B, Guo J, Zhou C, Gan Z, Yu J, Lu F. A review on microgrid technology with distributed energy. In international conference on smart grid and electrical automation 2017 (pp. 143-6). IEEE.

[2] Mizani S, Yazdani A. Optimal design and operation of a grid-connected microgrid. In Electrical Power \& Energy Conference 2009 (pp. 1-6). IEEE.

[3] Vijayan RJ, Ch S, Roy R. Dynamic modeling of micro grid for grid connected and intentional islanding operation. In international conference on advances in power conversion and energy technologies 2012 (pp. 1-6). IEEE

[4] Uddin M, Romlie MF, Abdullah MF, Hassan KN, Tan CK, Bakar AH. Modeling of campus microgrid for off-grid application. 5th IET international conference on clean energy and technology 2018 (pp.1-5).

[5] Baimel D, Belikov J, Guerrero JM, Levron Y. Dynamic modeling of networks, microgrids, and renewable sources in the dq0 reference frame: a survey. IEEE Access. 2017; 5:21323-35.

[6] Nordin AH, Omar AM. Modeling and simulation of Photovoltaic (PV) array and maximum power point tracker (MPPT) for grid-connected PV system. In international symposium \& exhibition in sustainable energy \& environment 2011 (pp. 114-9). IEEE.

[7] Hernández JC, Sanchez-Sutil F, Muñoz-Rodríguez FJ. Design criteria for the optimal sizing of a hybrid energy storage system in PV household-prosumers to maximize self-consumption and self-sufficiency. Energy. 2019; 186:1-21.

[8] Zhang F, Fu A, Ding L, Wu Q. MPC based control strategy for battery energy storage station in a grid with high photovoltaic power penetration. International Journal of Electrical Power \& Energy Systems. 2020; 115:1-9.

[9] Singh SN, ØSTERGAARD J, Jain N. Distributed generation in power systems: an overview and key issues. Fuel Cells. 2009; 9:1-9.

[10] Hemmes K. Towards multi-source multi-product and other integrated energy systems. International Journal of Integrated Energy Systems. 2009; 1(1):1-5. 
[11] Tsai CT, Shen TW, Chen YP, Hsu PH. Control strategy of $\mathrm{PV} /$ diesel/battery hybrid system for islandbased microgrid. In international symposium on computer, consumer and control (IS3C) 2018 (pp. 121-4). IEEE.

[12] Mahmud K, Hossain MJ, Ravishankar J. Peak-load management in commercial systems with electric vehicles. IEEE Systems Journal. 2018; 13(2):1872-82.

[13] Dagdougui H, Dessaint L, Gagnon G, Al-Haddad K. Modeling and optimal operation of a university campus microgrid. In power and energy society general meeting (PESGM) 2016 (pp. 1-5). IEEE.

[14] Mahmud K, Hossain MJ, Town GE. Peak-load reduction by coordinated response of photovoltaics, battery storage, and electric vehicles. IEEE Access. 2018; 6:29353-65.

[15] Rana MM, Romlie MF, Abdullah MF. Peak load shaving in isolated microgrid by using hybrid PVBESS system. International Journal. 2020; 8(1.1):714.

[16] Washom B, Dilliot J, Weil D, Kleissl J, Balac N, Torre W, Richter C. Ivory tower of power: microgrid implementation at the University of California, San Diego. IEEE Power and Energy Magazine. 2013; 11(4):28-32.

[17] AbdelHady R. Modeling and simulation of a micro grid-connected solar PV system. Water Science. 2017; 31(1):1-10.

[18] Khalil A, Ateea K. Modelling and control of photovoltaic-based microgrid. International Journal of Renewable Energy Research. 2015; 5(3):826-35.

[19] Uddin M, Romlie MF, Abdullah MF. Performance assessment and economic analysis of a gas-fueled islanded microgrid - a Malaysian case study. Infrastructures. 2019; 4(4):1-14.

[20] Atef M, Khatib T, Abdullah MF, Romlie MF. Optimization of a hybrid solar PV and gas turbine generator system using the loss of load probability index. Clean Technologies. 2020; 2(3):240-51.

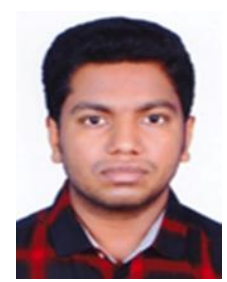

Md Masud Rana received the Bachelor of Science (BSc) in Electrical and Electronic Engineering from Prime University (PU), Dhaka, Bangladesh, in 2018. He is currently pursuing Master of Science (MSc) in Electrical and Electronic Engineering from Universiti Teknologi PETRONAS (UTP), Perak, Malaysia. His research interests include Micro Grid, Renewable Energy, Energy Storage System and Peak Load Shaving.

Email: md_19001506@utp.edu.my

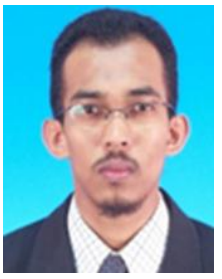

Mohd Fakhizan Romlie received the BSc degree in Electrical and Electronic Engineering from Universiti Teknologi PETRONAS (UTP), Perak, Malaysia, in 2004, the MSc degree in Power System Engineering from The University of Western Australia in 2006, and the PhD degree in Electrical Engineering from the University of Nottingham, U.K., in 2014. He is currently a Senior Lecturer in Universiti Teknologi PETRONAS. His research interests include Smart Grid, Renewable Energy, And Wireless Power Transfer.

Email: fakhizan.romlie@utp.edu.my

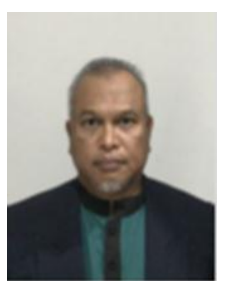

Mohd Faris Abdullah received the BSc degree in Electrical Power Engineering from Universiti Teknologi MARA (UiTM), Malaysia, in 1989, the MSc degree in Electrical Engineering from Universiti Tenaga Nasional (UNITEN), Malaysia, in 2006, and the $\mathrm{PhD}$ degree in Electrical and Electronic Engineering from Universiti Teknologi PETRONAS (UTP), Malaysia, in 2015. He is currently an Associate Professor in Universiti Teknologi PETRONAS. His research interests include Power System, Power Quality, and Renewable Energy.

Email: mfaris_abdullah@utp.edu.my

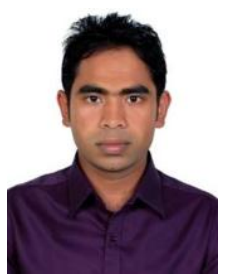

Moslem Uddin received the Bachelor of Science (BSc) in Electrical and Electronic Engineering from Prime University (PU), Dhaka, Bangladesh, in 2014, the Master of Science (MSc) in electrical and Electronic Engineering from Universiti Teknologi PETRONAS (UTP), Perak, Malaysia, in 2019. His research interests include Micro Grid, Energy Storage System, and Peak Load Shaving.

Email: moslem.uddin.bd@gmail.com

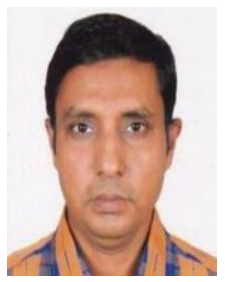

Mohammad Obaidur Rahman received the Bachelor of Science (BSc) in Electrical and Electronic Engineering from Presidency University, Dhaka, Bangladesh, in 2012, the Master of Science in Electrical and Electronic Engineering from Universiti Teknologi Malaysia (UTM), Johor Bahru, Malaysia, in 2015. He is currently pursuing $\mathrm{PhD}$ degree in electrical and electronic Engineering from Universiti Teknologi PETRONAS (UTP), Perak, Malaysia. His research interests include Renewable Energy and Energy Storage System.

Email: mohammad_18003517@utp.edu.my 